Pharmacokinetics of cefazolin for prophylactic administration to dogs

by

Omar J. González-Cintrón

B.S., University of Puerto Rico, 2007

D.V.M., Tuskegee University, 2013

\begin{abstract}
A Thesis
Master of Science

Department of Clinical Sciences

College of Veterinary Medicine
\end{abstract}

submitted in partial fulfillment of the requirements for the degree

Kansas State University

Manhattan, Kansas

2017

Approved by:

Major Professor

Walter Renberg, DVM, MS

Diplomate ACVS 


\section{Copyright}

C OMAR J. GONZÁLEZ-CINTRÓN

2017 


\begin{abstract}
OBJECTIVE: The purpose of the study reported here was to evaluate pharmacokinetics of cefazolin in dogs receiving a single IV injection of cefazolin $(22 \mathrm{mg} / \mathrm{kg})$ and $\mathrm{dogs}$ receiving simultaneous IV and IM injections of cefazolin (total dose, $44 \mathrm{mg} / \mathrm{kg}$ ).

METHODS: Twelve purpose-bred Beagles (6/group) were assigned to receive a single injection of cefazolin (22 mg/kg, IV) or simultaneous injections $(22 \mathrm{mg} / \mathrm{kg}, \mathrm{IV}$, and $22 \mathrm{mg} / \mathrm{kg}$, IM). Interstitial fluid was collected over a 5-hour period using ultrafiltration probes for pharmacokinetic analysis.
\end{abstract}

RESULTS: Mean cefazolin concentration in the interstitial fluid at 1, 1.5, 2, 3, 4, and 5 hours after injection was 39.6, 29.1, 21.1, 10.3, 6.4, and $2.7 \mu \mathrm{g} / \mathrm{mL}$, respectively, for the IV group and 38.3, 53.3, 46.4, 31.7, 19.1, and $8.9 \mu \mathrm{g} / \mathrm{mL}$, respectively, for the IV + IM group. The mean area under the concentration-time curve extrapolated to infinity, maximum concentration, half life and time to the maximum concentration was 74.99 and $154.16 \mathrm{~h} \cdot \mu \mathrm{g} / \mathrm{mL}, 37.3$ and 51.5 $\mu \mathrm{g} / \mathrm{mL}, 0.96$ and 1.11 hours, 1.28 and 1.65 hours, respectively, for the IV and IV + IM groups.

CONCLUSIONS AND CLINICAL RELEVANCE: Cefazolin concentrations in interstitial fluid of dogs were maintained at $>4 \mu \mathrm{g} / \mathrm{mL}$ for 4 hours after a single IV injection and for 5 hours after simultaneous IV and IM injections. Based on these results, simultaneous administration of cefazolin IV + IM 30 to 60 minutes before surgery should provide interstitial fluid concentrations effective against the most common commensal organisms (Staphylococcus spp and Streptococcus spp) on the skin of dogs for surgical procedures lasting $\leq 4$ hours. 


\section{Table of Contents}

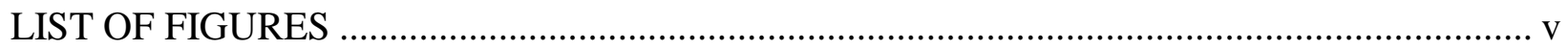

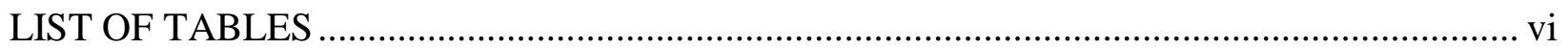

LIST OF ABBREVIATIONS ......................................................................................... vii

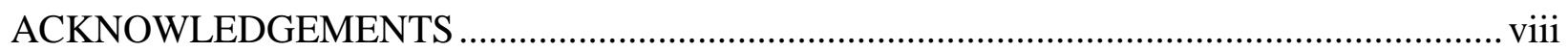

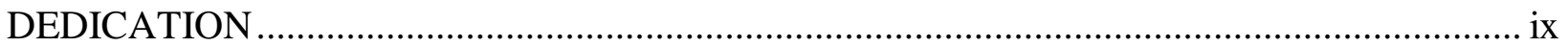

CHAPTER 1 - USE OF ANTIMICROBIAL PROPHYLAXIS DURING SURGERY ................ 1

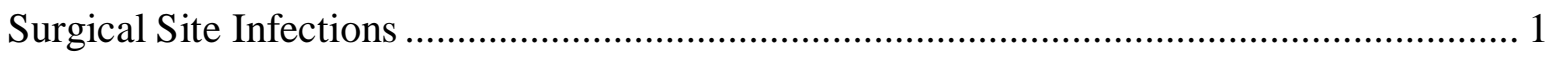

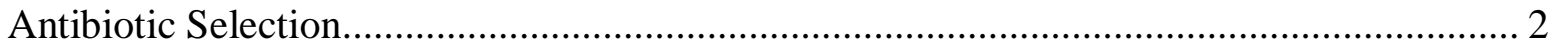

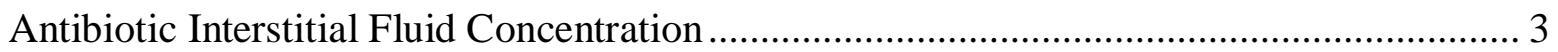

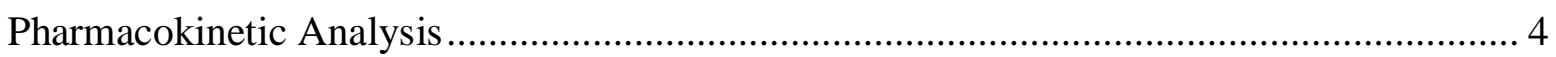

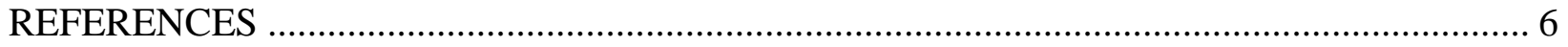

CHAPTER 2 - PHARMACOKINETICS OF CEFAZOLIN FOR PROPHYLACTIC

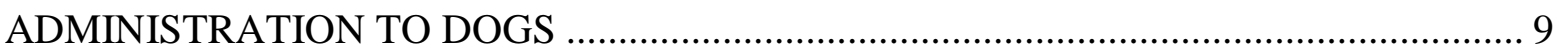

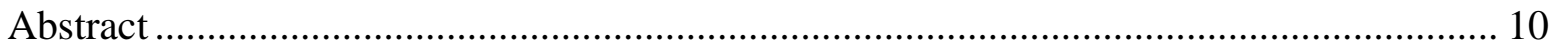

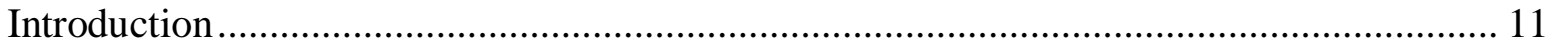

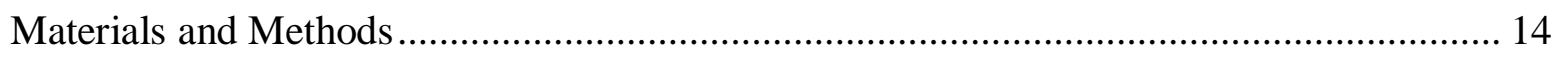

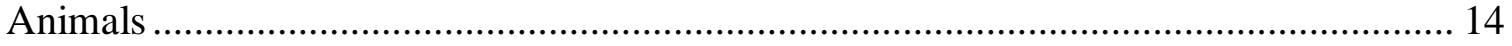

Implant placement ......................................................................................... 14

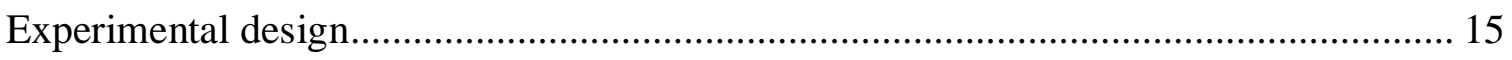

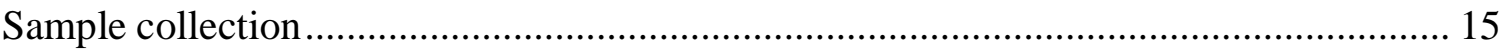

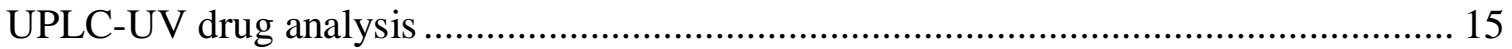

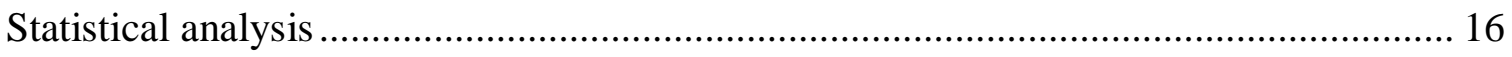

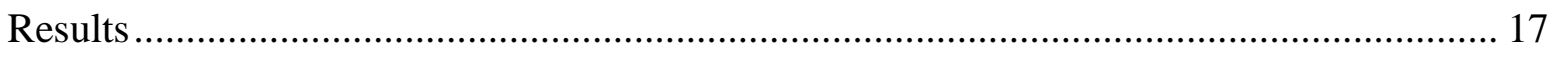

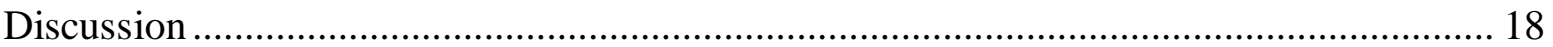

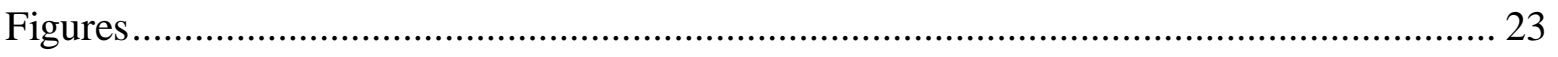

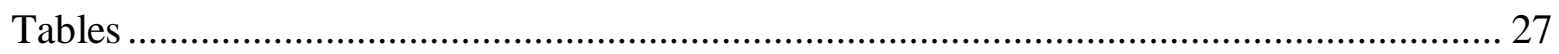

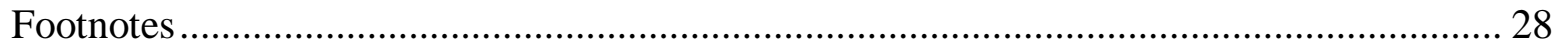

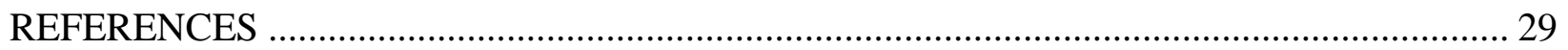

Appendix A - BASi ${ }^{\circledR}$ Ultrafiltration Probe Image ………………………………..................... 32 


\section{LIST OF FIGURES}

Figure 1 - Semipermeable ultrafiltration probe threaded from cranial to caudal into the introducer needle to be placed subcutaneously.

Figure 2 - Mean cefazolin concentration-time curve for concentrations in interstitial fluid after administration of a single dose (22 mg/kg, IV) to 5 dogs (IV group [circles]) and simultaneous IV and IM administration $(22 \mathrm{mg} / \mathrm{kg}, \mathrm{IV}$, and $22 \mathrm{mg} / \mathrm{kg}, \mathrm{IM})$ to $6 \mathrm{dogs}(\mathrm{IV}+$ IM group [squares]). Notice the $\mathrm{MIC}_{90}$ for Streptococcus $\mathrm{spp}(4 \mu \mathrm{g} / \mathrm{mL}$ [dashed line] ) and the $\mathrm{MIC}_{90}$ for Staphylococcus pseudintermedius $(2 \mu \mathrm{g} / \mathrm{mL}$ [dotted line]).

Figure 3 - Cefazolin concentration-time curves of the mean (squares), minimum (circles), and maximum (triangles) concentrations in interstitial fluid after administration of a single dose (22 mg/kg, IV) to 5 dogs (IV group [A]). Notice the MIC 90 for Streptococcus spp (4 $\mu \mathrm{g} / \mathrm{mL}$ [dashed line]) and the MIC90 for Staphylococcus pseudintermedius ( $2 \mu \mathrm{g} / \mathrm{mL}$ [dotted line]).

Figure 4 - Cefazolin concentration-time curves of the mean (squares), minimum (circles), and maximum (triangles) concentrations in interstitial fluid after administration of a simultaneous IV and IM administration $(22 \mathrm{mg} / \mathrm{kg}, \mathrm{IV}$, and $22 \mathrm{mg} / \mathrm{kg}, \mathrm{IM})$ to $6 \mathrm{dogs}(\mathrm{IV}+$ IM group [B]). Notice the MIC90 for Streptococcus spp (4 $\mathrm{g} / \mathrm{mL}$ [dashed line]) and the $\mathrm{MIC}_{90}$ for Staphylococcus pseudintermedius $(2 \mu \mathrm{g} / \mathrm{mL}$ [dotted line]).

Figure A.1 UF-3-12 ultrafiltration sampling probe used in this study, with $29 \mu \mathrm{L}$ volume capacity. 


\section{LIST OF TABLES}

Table 1 - Mean, minimum, and maximum concentrations of cefazolin $(\mu \mathrm{g} / \mathrm{kg})$ in interstitial fluid after administration of a single dose (22 $\mathrm{mg} / \mathrm{kg}$, IV) to $5 \mathrm{dogs}$ (IV group) and simultaneous IV and IM administration (22 mg/kg, IV, and $22 \mathrm{mg} / \mathrm{kg}, \mathrm{IM})$ to $6 \mathrm{dogs}$ (IV + IM group)... 27

Table 2 - Pharmacokinetics of cefazolin after administration of a single dose $(22 \mathrm{mg} / \mathrm{kg}$, IV) to 5 dogs (IV group) and simultaneous IV and IM administration (22 mg/kg, IV, and $22 \mathrm{mg} / \mathrm{kg}$, IM) to 6 dogs (IV + IM group). 


\section{LIST OF ABBREVIATIONS}

AUC Area under the concentration-time curve

AUCINF Area under the concentration-time curve extrapolated to infinity

HPLC High performance liquid chromatography

Cmax Maximum concentration in interstitial fluid

MIC Minimum inhibitory concentration

MIC90 Minimum inhibitory concentration at which $90 \%$ of isolates are inhibited

SSI Surgical site infection

$\mathrm{t}_{1 / 2} \quad$ Terminal half-life

tmax Time of the maximum concentration in interstitial fluid

UPLC-UV Ultraperformance liquid chromatography with UV detection 


\section{ACKNOWLEDGEMENTS}

I would like to acknowledge my masters committee Dr. Walter Renberg, Dr. James Roush and Dr. Butch Kukanich for the help and support developing this project. I would also like to acknowledge Dr. Emily Klocke and Dr. April Haynes for their mentorship and support throughout the residency program.

Finally I would like to thank Matt Warner for his laboratory assistance and Kimberly

Kalosy, Nathan Kapaldo, Akaterina Davros, Stefanie Campbell, Amanda Schlagel, Qiuwen Kou and Samantha Belsan for their help on the data collection. 


\section{DEDICATION}

This thesis is dedicated to my beautiful wife Xismari and my son William, without them none of this would have been possible. Thank you for believing in me and for all the support and understanding throughout this journey. 


\section{CHAPTER 1 - USE OF ANTIMICROBIAL PROPHYLAXIS}

\section{DURING SURGERY}

The use of peri-operative antibiotics to decrease the incidence of surgical-site infections (SSI) has been well established. ${ }^{1-6}$ Antimicrobials are recommended in procedures associated with high risk of infection or when postoperative infection would have catastrophic consequences on the outcome of surgery. ${ }^{3,7-9}$ In humans and animals, SSI can be a devastating complication, prolong the length of hospital stay and dramatically increase medical costs. ${ }^{5,10,11}$ There are some important concepts associated with the use of antimicrobial prophylaxis and they will be discussed in this report.

\section{Surgical Site Infections}

There is conflicting evidence of the efficacy of prophylactic antimicrobials in veterinary medicine, with some studies ${ }^{12}$ showing no effect and other studies showing a decrease in the incidence of SSI for routine clean surgical procedures. ${ }^{3,13}$ A randomized blinded prospective controlled study showed that the infection rate for control dogs was significantly higher (15.7\%) than the rate for dogs treated with peri-operative antimicrobials $(3.8 \%){ }^{3}$ In another study, 347 of 365 dogs $(95.3 \%)$ that underwent orthopedic surgery received peri-operative antibiotics. Five of $347(0.01 \%)$ developed SSI, whereas 3 of $16(18.7 \%)$ that did not receive peri-operative antibiotic developed SSI. ${ }^{13}$ Other studies have shown an overall infection rate between $5.9 \%$ and $8.9 \%$ for a variety of clean and clean-contaminated procedures with a conclusion that prophylaxis was not required for these procedures. ${ }^{14-16}$

Bacterial drug resistance (including multi-drug resistant bacteria), increased risk of hospital-acquired infection, and increased cost of the medical care are possible consequences of inappropriate or indiscriminate use of antimicrobials. ${ }^{1,15,17-19}$ A study in humans showed that antimicrobial prophylaxis was often not consistent with local or national guidelines; redosing schedule was followed at an appropriate time only in $40 \%$ of the cases but improved to $68 \%$ with an automatic reminder system. ${ }^{20} \mathrm{~A}$ different study in humans from a tertiary teaching hospital found that only 3 per cent of the procedures received an appropriate medication, dose, duration 
and redose timing according to the hospital guidelines. ${ }^{19}$ Similarly, dogs undergoing orthopedic surgery showed discrepancies between standard recommendations and the antimicrobial prophylaxis used. Sixteen per cent of the dogs did not receive the drug within 60 minutes of surgery, $19 \%$ received unnecessary repeated doses and $49 \%$ received additional doses at an incorrect time. ${ }^{15}$

Multiple studies have shown that the timing of antibiotic administration and redosing schedule are not always performed according to the institution guidelines. One study found that $78 \%$ of dogs received the first antimicrobial dose before surgery; out of these dogs $84 \%$ received the dose within 60 minutes of the first incision. Twelve percent of dogs were initially treated during surgery, 10 to 165 minutes after the first incision. If a guideline of repeated administration every 90 minutes after the first administration until closure of the surgical-site was used, $51 \%$ dogs received the required intraoperative administration, and $19 \%$ of dogs that did not require intraoperative dosing were treated. ${ }^{12}$ A more recent study showed a redosing incidence of $93.5 \%$, which they considered excellent; however, $28.4 \%$ of dogs received antimicrobials late, with the dose being administered more than 30 minutes late in $28 \%$ of those dogs. ${ }^{21}$

\section{Antibiotic Selection}

The antibiotic selected for prophylactic use must be effective against the pathogen most likely to cause postoperative wound infection. ${ }^{3,7,8}$ Antibiotics with efficacy against commonly encountered pathogens, such as Staphylococcus spp., Streptococcus spp. and sometimes Escherichia coli, are usually recommended in veterinary medicine based on the location of the surgery. In order for antimicrobial prophylaxis to be effective, it must be present at the surgicalsite at an adequate concentration before the time of contamination and throughout the surgical procedure. ${ }^{6-8,22,23}$

Cephalosporins are effective antimicrobials, well tolerated, and obtain targeted serum and tissue concentrations. ${ }^{9}$ Cefazolin has been recommended as the ideal prophylactic antibiotic for surgery in dogs and has become one of the most common antimicrobials for peri-operative use because of its spectrum, low incidence of adverse effects, and low cost. ${ }^{3,7,8,24}$ The beta-lactam antimicrobials (penicillins and cephalosporins) are time-dependent, meaning that efficacy is correlated with the time that drug concentration remains above the minimum inhibitory 
concentration (MIC) for a particular pathogen. ${ }^{7,25}$ Based on pharmacokinetic studies it has been recommended for time-dependent antimicrobials such as beta-lactams to be redosed intraoperatively every 2 half-lives in order to maintain targeted plasma concentrations. ${ }^{7,8,12,24}$

Cefazolin is not appreciably absorbed after oral administration and must be given parenterally to achieve therapeutic serum levels. Absorbed drug is excreted unchanged by the kidneys into the urine. Elimination half-lives may be significantly prolonged in patients with severely diminished renal function. In dogs, peak levels occur in about 30 minutes after IM administration. The apparent volume of distribution at steady state is $700 \mathrm{~mL} / \mathrm{kg}$, total body clearance of $10.4 \mathrm{~mL} / \mathrm{min} / \mathrm{kg}$ with a serum elimination half-life of 48 minutes. Approximately $64 \%$ of the clearance can be attributed to renal tubular secretion. The drug is approximately 16$28 \%$ bound to plasma proteins in dogs. ${ }^{26}$

\section{Antibiotic Interstitial Fluid Concentration}

Protein binding is a major factor in the tissue distribution of a drug. ${ }^{22}$ In order to predict antimicrobial activity, it is important to know the concentration of the protein-unbound antimicrobial at the site of bacterial contamination (surgical-site). A previous study has suggested that the concentration of cefazolin in the ISF is similar to plasma due to rapid equilibration of cefazolin between serum and soft tissues in the surgical wound. ${ }^{8}$ To date, only two studies have measured and compared the concentration of cefazolin in the surgical-site to serum by obtaining muscle biopsies and determining the antibiotic concentration by the use of a modified agar plate diffusion technique. ${ }^{7,23}$ However, tissue concentrations may underestimate true surgical site concentrations as the interstitial fluid is diluted with the intracellular fluid. One alternative to determine the antibiotic concentration in the interstitial fluid is the utilization of tissue cages and by ultrafiltration.

The concentration of antibacterial agents in the interstitial tissue fluid has been studied in an experimental model using implanted perforated Silastic capsules (tissue cages). The lining within the cage contains young fibroblasts, many capillaries, and obvious tissue spaces. The rate of diffusion into and out of the cage fluid of small molecules, such as sodium, is rapid, whereas for larger molecules, such as albumin, it is slower. ${ }^{27-29}$ These tissue cages, however, need to be 
implanted 4 weeks prior to the sampling collection to allow ingrowth of cells into the cages and production of interstitial fluid.

On the other hand, some researchers have used ultrafiltration. Ultrafiltration provides a means for collecting protein-unbound cefazolin in the ISF by use of an implanted semipermeable

membrane in the tissue. Previous studies ${ }^{30-32}$ have shown that an ultrafiltration device is a reliable and convenient method for collecting ISF samples from tissues in dogs. This device has become the preferred method for collecting ISF, rather than collection of tissue biopsy specimens or use of tissue cages, because of anatomic and physiologic relevance, lack of contamination from intracellular content, ease of insertion, the ability to collect serial samples with the same device, and monitoring of drug distribution in unrestrained animals. Furthermore, the ultrafiltration device provides a convenient method for continuous sample collection without residual wounds or lesions after removal of the ultrafiltration probes. ${ }^{22}$

\section{Pharmacokinetic Analysis}

Reversed-phase gradient high performance liquid chromatography (HPLC) has become the preferred method for drug discovery and drug metabolism studies. ${ }^{33}$ HPLC is a technique in analytical chemistry used to separate, identify, and quantify each component in a mixture. It relies on pumps to pass a pressurized liquid solvent, containing the sample mixture, through a column filled with a solid adsorbent material. Each component in the sample interacts slightly differently with the adsorbent material, causing different flow rates for the different components and leading to the separation of the components as they flow out the column. The coupling of a mass spectrometer with liquid chromatography, and the advent of atmospheric pressure ionization interfaces, have resulted in significant improvements in sensitivity and specificity of analytical assays. ${ }^{33}$

Chromatography can be described as a mass transfer process involving adsorption. HPLC relies on a column filled with adsorbent. The active component of the column, the adsorbent, is typically a granular material made of solid particles 2-50 micrometers in size. The components of the sample mixture are separated from each other due to their different degrees of interaction with the adsorbent particles. The pressurized liquid is typically a mixture of solvents and is referred to as a "mobile phase". Its composition and temperature play a major role in the 
separation process by influencing the interactions taking place between sample components and adsorbent. The concentrations of cefazolin in interstitial fluid can be determined by use of ultraperformance liquid chromatography coupled with ultraviolet detection (UPLC-UV). 


\section{REFERENCES}

1. Brown DC, Conzemius MG, Shofer S, et al. Epidemiologic evaluation of postoperative wound infections in dogs and cats. J Am Vet Med Assoc 1997;210:1302-1306.

2. Kenneth SS, Wroczynski F, Jones CW. Duration of antibiotic prophylaxis. Am J Surg 1986;151:209-212.1

3. Whittem TL, Johnson AL, Smith CW, et al. Effect of perioperative prophylactic antimicrobial treatment in dogs undergoing elective orthopedic surgery. J Am Vet Med Assoc 1999;215:212-216.

4. Prospero E, Barbadoro P, Marigliano A, et al. Perioperative antibiotic prophylaxis: improved compliance and impact on infection rates. Epidemiol Infect 2011;139:13261331.

5. Xu SG, Mao ZG, Liu BS, et al. Evaluating the use of antibiotic prophylaxis during open reduction and internal fixation surgery in patients at low risk of surgical site infection. Injury 2015;46:184-188.

6. Kaiser AB. Antimicrobial prophylaxis in surgery. N Engl J Med 1986;315:1129-1138.

7. Rosin E, Uphoff TS, Schultz-Darken NJ, et al. Cefazolin antibacterial activity and concentrations in serum and the surgical wound in dogs. Am J Vet Res 1993;54:13171321.

8. Marcellin-Little DJ, Papich MG, Richardson DC, et al. Pharmacokinetic model for cefazolin distribution during total hip arthroplasty in dogs. Am J Vet Res 1996;57:720 723.

9. Wilkens B, Sullivan P, McDonald TP, et al. Effects of cephalothin, cefazolin, and cefmetazole on the hemostatic mechanism in normal dogs: implications for the surgical patient. Vet Surg 1995;24:25-31.

10. Hauser CJ, Adams CA Jr, Eachempati SR. Surgical Infection Society guideline: prophylactic antibiotic use in open fractures: an evidence-based guideline. Surg Infect (Larchmt) 2006;7:379-405.

11. Mangram AJ, Horan TC, Pearson ML, et al. Guideline for prevention of surgical site infection. Am J Infect Control 1999;27:97-132.

12. Weese JS, Halling KB. Perioperative administration of antimicrobials associated with elective surgery for cranial cruciate ligament rupture in dogs: 83 cases (2003-2005). $J$ Am Vet Med Assoc 2006;229:92-95. 
13. Casale SA, McCarthy RJ. Complications associated with lateral fabellotibial suture surgery for cranial cruciate ligament injury in dogs: 363 cases (1997-2005). J Am Vet Med Assoc 2009;234:229-235.

14. Nicholson M, Beal M, Shofer F, et al. Epidemiologic evaluation of postoperative wound infection in clean-contaminated wounds: a retrospective study of 239 dogs and cats. Vet Surg 2002;31:577-581.

15. Knights CB, Mateus A, Baines SJ. Current British veterinary attitudes to the use of perioperative antimicrobials in small animal surgery. Vet Rec 2012;170:646-652.

16. Daude-Lagrave A, Carozzo C, Fayolle P, et al. Infection rates in surgical procedures: a comparison of cefalexin vs a placebo. Vet Comp Orthop Traumatol 2001;14:146-150.

17. Martin C, Pourriat JL. Quality of postoperative antibiotic administration by French anaesthetists. J Hosp Infect 1998;40:47-53.

18. Song F, Glenny AM. Antimicrobial prophylaxis in colorectal surgery: a systematic review of randomized controlled trials. Br J Surg 1998;85:1232-1241.

19. Heineck I, Ferreira MB, Schenkel EP. Prescribing practice for antibiotic prophylaxis for 3 commonly performed surgeries in a teaching hospital in Brazil. Am J Infect Control 1999;27:296-300.

20. Zanetti G, Flanagan HL, Cohn LH, et al. Improvement of intraoperative antibiotic prophylaxis in prolonged cardiac surgery by automated alerts in the operating room. Infect Control Hosp Epidemiol 2003;24:13-16.

21. Kenneth SS, Wroczynski F, Jones CW. Duration of antibiotic prophylaxis. Am J Surg 1986;151:209-212.1

22. Rosin E, Ebert S, Uphoff TS, et al. Penetration of antibiotics into the surgical wound in a canine model. Antimicrob Agents Chemother 1989;33:700-704.

23. Nazarali A, Singh A, Weese JS. Perioperative administration of antimicrobials during tibial plateau leveling osteotomy. Vet Surg 2014;43:966-971.

24. Papich MG, Davis JL, Floerchinger AM. Pharmacokinetics, protein binding, and tissue distribution of orally administered cefpodoxime proxetil and cephalexin in dogs. Am J Vet Res 2010;71:1484-1491.

25. Petersen SW, Rosin E. Cephalothin and cefazolin in vitro antibacterial activity and pharmacokinetics in dogs. Vet Surg 1995;24:347-351.

26. Plumb DC(2011). Plumb's Veterinary Drug Handbook. Stockholm, WI. PharmaVet Inc. 
27. Chisholm GD, Waterworth PA, Calnan JS, Garrod LP. Concentration of Antibacterial Agents in Interstitial Tissue Fluid. British Medical Journal, 1973;1:569-573.

28. Cars O. Tissue distribution of beta-lactam antibiotics. Experimental studies in rabbits. Scand J Infect Dis Suppl. 1981;27:1-48.

29. Ganzinger U, Schiel H, Georgopoulos A, Gumhold G. The utility of diffusion chambers as models for the description of drug disposition. J Antimicrob

Chemother. 1986;18(1):93-102.

30. Bidgood TL, Papich MG. Comparison of plasma and interstitial fluid concentrations of doxycycline and meropenem following constant rate intravenous infusion in dogs. Am $J$ Vet Res 2003;64:1040-1046.

31. Bidgood TL, Papich MG. Plasma and interstitial fluid pharmacokinetics of enrofloxacin, its metabolite ciprofloxacin, and marbofloxacin after oral administration and a constant rate intravenous infusion in dogs. $J$ Vet Pharmacol Ther 2005;28:329-341.

32. Bidgood TL, Papich MG. Plasma pharmacokinetics and tissue fluid concentrations of meropenem after intravenous and subcutaneous administration in dogs. Am J Vet Res 2002;63:1622-1628.

33. Cheng YF, Lu Z, Neue U. Ultrafast liquid chromatography/ultraviolet and liquid chromatography/tandem mass spectrometric analysis. Rapid Commun. Mass Spectrom 2001;15:141-151. 


\title{
CHAPTER 2 - PHARMACOKINETICS OF CEFAZOLIN FOR PROPHYLACTIC ADMINISTRATION TO DOGS
}

This portion of the thesis contains a version of a manuscript submitted for consideration for publication in the American Journal of Veterinary Research in June 2016

"Pharmacokinetics of cefazolin for prophylactic administration to dogs"

\author{
Omar J. Gonzalez DVM ${ }^{1}$ \\ Walter C. Renberg DVM, MS ${ }^{1}$ \\ James K. Roush DVM, MS ${ }^{1}$ \\ Butch KuKanich DVM, $\mathrm{PhD}^{2}$ \\ Matt Warner, $\mathrm{MS}^{2}$
}

${ }^{1}$ Department of Clinical Sciences, College of Veterinary Medicine, Kansas State University, Manhattan, KS 66506.

${ }^{2}$ Department of Anatomy and Physiology, College of Veterinary Medicine, Kansas State University, Manhattan, KS 66506.

This study was funded by an institutional grant from the Department of Clinical Sciences and by the Dean's office of the College of Veterinary Medicine, Kansas State University 


\begin{abstract}
OBJECTIVE

To evaluate pharmacokinetics of cefazolin after a single IV injection of cefazolin (22 $\mathrm{mg} / \mathrm{kg}$ ) and after simultaneous IV and IM injections of cefazolin (total dose, $44 \mathrm{mg} / \mathrm{kg}$ ) to dogs.
\end{abstract}

\title{
ANIMALS
}

12 adult Beagles.

\section{PROCEDURES}

Dogs (6/group) were assigned to receive a single injection of cefazolin (22 mg/kg, IV) or simultaneous injections ( $22 \mathrm{mg} / \mathrm{kg}, \mathrm{IV}$, and $22 \mathrm{mg} / \mathrm{kg}$, IM). Interstitial fluid was collected over a 5-hour period using ultrafiltration probes for pharmacokinetic analysis.

\section{RESULTS}

Mean cefazolin concentration in the interstitial fluid at 1, 1.5, 2, 3, 4, and 5 hours after injection was 39.6, 29.1, 21.1, 10.3, 6.4, and $2.7 \mu \mathrm{g} / \mathrm{mL}$, respectively, for the IV group and 38.3, 53.3, 46.4, 31.7, 19.1, and $8.9 \mu \mathrm{g} / \mathrm{mL}$, respectively, for the IV + IM group. The mean area under the concentration-time curve extrapolated to infinity, maximum concentration, half life and time to the maximum concentration was 74.99 and $154.16 \mathrm{~h} \cdot \mu \mathrm{g} / \mathrm{mL}, 37.3$ and $51.5 \mu \mathrm{g} / \mathrm{mL}, 0.96$ and 1.11 hours, 1.28 and 1.65 hours, respectively, for the IV and IV + IM groups.

\section{CONCLUSIONS AND CLINICAL RELEVANCE}

Cefazolin concentrations in interstitial fluid of dogs were maintained at $>4 \mu \mathrm{g} / \mathrm{mL}$ for 4 hours after a single IV injection and for 5 hours after simultaneous IV and IM injections. Based on these results, simultaneous administration of cefazolin IV + IM 30 to 60 minutes before surgery should provide interstitial fluid concentrations effective against the most common commensal organisms (Staphylococcus spp and Streptococcus spp) on the skin of dogs for surgical procedures lasting $\leq 4$ hours. 


\section{Introduction}

It has been clearly established that perioperative administration of antimicrobials can decrease the incidence of SSIs. ${ }^{1-6}$ Antimicrobials are recommended for procedures associated with high risk of infection or when postoperative infection would have catastrophic consequences on the outcome of surgery. ${ }^{3,7-9}$ In humans and other animals, SSI can be a devastating complication, prolong the duration of hospital stay, and dramatically increase medical costs. $5,10,11$ There is conflicting evidence about the efficacy of prophylactic administration of antimicrobials in veterinary medicine; one investigator detected no effect, ${ }^{12}$ whereas other investigators detected a decrease in the incidence of SSI for routine clean surgical procedures. ${ }^{3,13}$ In a randomized blinded prospective controlled study, ${ }^{3}$ the infection rate for control dogs $(15.7 \%)$ was significantly higher than the rate for dogs treated perioperatively with antimicrobials (3.8\%). In another study, ${ }^{13} 347$ of 365 (95.3\%) dogs that underwent orthopedic surgery received antimicrobials perioperatively. Only 5 of those $347(0.01 \%)$ dogs developed SSI, whereas 3 of $16(18.7 \%)$ dogs that did not receive antimicrobials perioperatively developed SSI. Investigators of other studies ${ }^{14-16}$ have found an overall infection rate between $5.9 \%$ and $8.9 \%$ for a variety of clean and clean-contaminated procedures, and they have concluded that prophylactic antimicrobial administration was not required for these procedures.

Antimicrobial-resistant bacteria (including multidrug resistant bacteria), increased risk of hospital-acquired infection, and increased cost of medical care are possible consequences of inappropriate or indiscriminate use of antimicrobials. ${ }^{1,15,17-19}$ Current guidelines in human medicine include use of antimicrobials only in clean-contaminated, contaminated, or dirty procedures; administration of the first dose of antimicrobial 1 hour before the first incision; readministration of the antimicrobial during surgery if the procedure is still ongoing after 2 halflives of the drug have passed; restriction of treatment to the duration of surgery or for 24 hours, except in certain situations (i.e., gross contamination or preexisting infection); and avoiding use of newer broad-spectrum antimicrobials. ${ }^{12}$ In 1 study, ${ }^{20}$ prophylactic administration of antimicrobials to humans was often not consistent with local or national guidelines because a redosing schedule was followed at an appropriate time in only $40 \%$ of the patients, although this

improved to $68 \%$ when an automatic reminder system was used. In another study ${ }^{19}$ of humans at a tertiary teaching hospital, an appropriate medication, dose, duration, and redosing schedule in 
accordance with the hospital guidelines was used for only $3 \%$ of the patients. Similarly, there are discrepancies antimicrobial use and standard recommendations with regard to timing of administration before and during surgery, duration, and antimicrobial prophylaxis for dogs undergoing orthopedic surgery. In 1 study, ${ }^{15} 16 \%$ of the dogs did not receive the antimicrobial within 60 minutes after surgery, 19\% received unnecessary repeated doses of the antimicrobial, and $49 \%$ received additional doses of the antimicrobial at an incorrect time.

The antimicrobial selected for prophylactic use must be effective against the pathogen or pathogens most likely to cause postoperative wound infection. ${ }^{3,7,8}$ Antimicrobials with efficacy against commonly encountered pathogens, such as Staphylococcus spp, Streptococcus spp, and sometimes Escherichia coli, are usually recommended for use in veterinary medicine on the basis of the surgery location. Cephalosporins are effective antimicrobials, are tolerated well, and achieve targeted serum and tissue concentrations. ${ }^{9}$ Cefazolin has been recommended as the ideal prophylactic antimicrobial for surgery in dogs and has become one of the antimicrobials most commonly used perioperatively because of its spectrum, low incidence of adverse effects, and low cost. ${ }^{3,7,8,21}$ For antimicrobial prophylaxis to be effective, an adequate concentration of the drug must be present at the surgical site before the time of contamination and throughout the surgical procedure. ${ }^{6-8,22,23}$ The $\beta$-lactam antimicrobials (penicillins and cephalosporins) are timedependent drugs, which means that efficacy is correlated with the amount of time that drug concentration remain above the MIC for a particular pathogen. ${ }^{7,24}$ On the basis of results of pharmacokinetic studies, ${ }^{7,8,12,23}$ it has been recommended that time-dependent antimicrobials such as $\beta$-lactams should be readministered every 2 half-lives during surgery to maintain targeted plasma concentrations.

In a previous study, ${ }^{8}$ it was suggested that the concentration of cefazolin in the interstitial fluid is similar to the concentration in plasma owing to rapid equilibration of cefazolin between serum and soft tissues in a surgical wound. To our knowledge, the concentration of cefazolin in the surgical site has been measured and compared with serum concentrations (by obtaining muscle biopsy specimens and determining the antimicrobial concentration with a modified agar plate diffusion technique) in only 2 studies. ${ }^{7,22}$ However, tissue concentrations may underestimate true surgical site concentrations because the interstitial fluid is diluted with 
intracellular fluid. An ultrafiltration probe has been used to obtain interstitial fluid in other studies. ${ }^{25-27}$ It has been found that this is a reliable, easily performed, and useful method for the evaluation of drug disposition in dogs, and it eliminates the need for collection of tissue samples or use of tissue cages to estimate concentrations in tissues.

The purpose of the study reported here was to compare the cefazolin concentration in interstitial fluid obtained from dogs receiving a single IV injection of cefazolin and dogs receiving simultaneous IV and IM injections of cefazolin. We hypothesized that the concentration in the interstitial fluid would be higher and more prolonged in the group receiving simultaneous IV and IM injections, compared with results for the group receiving only an IV injection. 


\section{Materials and Methods}

\section{Animals}

Twelve purpose-bred Beagles (6 males and 6 females) were used in the study. All dogs were 1 year old and considered healthy; a physical examination, $\mathrm{CBC}$, and serum biochemical profile were performed to verify health of the dogs. All dogs had an albumin concentration $>3.4$ $\mathrm{g} / \mathrm{dL}$ (range, 3.4 to $4.2 \mathrm{~g} / \mathrm{dL}$ ). All dogs were allowed to acclimatize to the environment before initiation of the study. The study was reviewed and approved by the Institutional Animal Care and Use Committee at Kansas State University.

\section{Implant placement}

Dogs were sedated with dexmedetomidine hydrochloride ${ }^{\mathrm{a}}(15 \mu \mathrm{g} / \mathrm{kg}, \mathrm{IV})$. An indwelling percutaneous catheter was placed in the jugular vein, and 2 ultrafiltration probes ${ }^{\mathrm{b}}$ were placed in the dorsum of each dog. The ultrafiltration probes contained 3 loops with a $12-\mathrm{cm}$ semipermeable membrane. The semipermeable membrane in the loop consisted of pores that allowed water, electrolytes, and low-molecular-weight (<30 KDa) molecules to diffuse across the membrane but excluded the passage of proteins, protein-bound drugs, and other highmolecular-weight compounds. For insertion of the ultrafiltration probes, an area $(2.5 \mathrm{~cm}$ on each side of the midline at the dorsal caudolateral aspect of the scapulae) was shaved and aseptically prepared. One of the insertion sites was infused with a solution of $2 \%$ lidocaine hydrochloride $^{c}$ $(1 \mathrm{mg} / \mathrm{kg})$, a stab incision was made through the skin with a No. 11 scalpel blade, and subcutaneous tissues were identified. An introducer needle was inserted in the stab incision, advanced cranially through the subcutaneous tissues for a distance of $10 \mathrm{~cm}$, and exited through the skin; the ultrafiltration probe was then threaded through the needle from a cranial to caudal direction (Figure1) until the tip of the probe was flush with the tip of the introducer needle. The introducer needle containing the probe was then retracted $3 \mathrm{~cm}$ so that the 3 loops of the probe remained under the skin in the interstitial space and the nonpermeable portion of the probe remained external to the dog's skin. The ultrafiltration probe was then secured to the skin with a

non-absorbable nylon suture ${ }^{\mathrm{d}}$ by use of a finger-trap pattern. A vacuum-vial needle ${ }^{\mathrm{e}}$ was attached to the ultrafiltration probe tubing, and a collection tube was attached to that needle to apply 
negative pressure on the probe system for collection of interstitial fluid through the semipermeable membrane. The probe insertion procedure then was repeated for the opposite side. After the ultrafiltration probes were inserted, sedation was reversed by administration of atipamezole hydrochloride ${ }^{\mathrm{f}}(2.4 \mathrm{mg} / \mathrm{kg}, \mathrm{IM})$. The initial collection tubes were allowed to remain in place for $\geq 18$ hours to equilibrate the system before the initiation of the study.

\section{Experimental design}

Dogs were assigned to 2 groups (6 dogs/group) by use of randomizing software. ${ }^{\mathrm{g}}$ At 24 hours after placement of the IV catheter and filtration probes, dogs of one group (IV group) received an injection of cefazolin ${ }^{\mathrm{h}}(22 \mathrm{mg} / \mathrm{kg}$, IV) and dogs of the other group (IV + IM group) received simultaneous IV and IM injections of cefazolin $(22 \mathrm{mg} / \mathrm{kg}, \mathrm{IV}$, and $22 \mathrm{mg} / \mathrm{kg}, \mathrm{IM})$.

\section{Sample collection}

Interstitial fluid was collected in a microcentrifuge tube ${ }^{\mathrm{i}}$ inserted in a red top vacuum

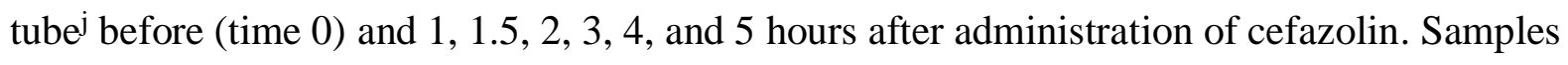
were immediately placed on ice. All samples subsequently were stored at $-70^{\circ} \mathrm{C}$ until testing was performed.

\section{UPLC-UV drug analysis}

Concentrations of cefazolin in interstitial fluid were determined by use of UPLC-UV ${ }^{\mathrm{k}}$ at $271 \mathrm{~nm}$. The mobile phase consisted of $1.7 \%$ formic acid in deionized water (solution A) and 1\% formic acid in acetonitrile (solution B). The mobile phase gradient started at $90 \%$ solution A, decreased to $30 \%$ solution A from 0.1 to 2 minutes, decreased to $14.2 \%$ solution A at 2.5 minutes, and increased to $90 \%$ solution $\mathrm{A}$ at 2.51 minutes (total run time, 3.5 minutes). A C18 column $n^{1}$ maintained at $40^{\circ} \mathrm{C}$ was used for separation. The sample tray was maintained at $4{ }^{\circ} \mathrm{C}$, and injection volume was $5 \mu \mathrm{L}$. Interstitial fluid samples were injected directly into the UPLCUV without prior treatment. Standard curve and quality control samples were created with pooled canine interstitial fluid (linear range, 0.25 to $250 \mu \mathrm{g} / \mathrm{mL}$ ). Accuracy of the assay determined by use of 6 replicates each for concentrations of $0.25,5$, and $250 \mu \mathrm{g} / \mathrm{mL}$ was $103 \%$, $104 \%$, and $92 \%$ of the actual concentration, respectively. Coefficient of variation for the assay 
determined by use of 6 replicates each for concentrations of $0.25,5$, and $250 \mu \mathrm{g} / \mathrm{mL}$ was $8 \%$, $9 \%$, and $6 \%$, respectively.

\section{Statistical analysis}

Statistical analysis of the concentration-time curve was performed with a commercially available software package. ${ }^{\mathrm{m}}$ Data were tested for equality of variance, and values for individual time points $(1,1.5,2,3,4$, and 5 hours) were compared between the 2 groups by use of an independent group means test. Pharmacokinetic analysis of interstitial fluid concentrations was performed with noncompartmental methods by use of computer software. ${ }^{\mathrm{n}}$ Interstitial fluid pharmacokinetic parameters (AUC INF [determined by use of the linear trapezoidal method] and $\mathrm{t}_{1 / 2}$ ) were calculated for each dog, and descriptive statistics (geometric mean, minimum, and maximum values) were reported. ${ }^{28}$ Values for Cmax and tmax were determined directly from the data. Statistical analysis of pharmacokinetic data was conducted with computer software ${ }^{\circ}$ by use of the Mann-Whitney rank sum test. ${ }^{29}$ Values were considered significant at $P<0.05$ 


\section{Results}

The IV group initially consisted of 3 males and 3 females; however, 1 male was removed from the study because the dog removed the ultrafiltration devices before the initiation of the sample collection period. Thus, data were collected for 5 dogs in the IV group (mean body weight, $8.7 \mathrm{~kg}$; range, 7.4 to $10.8 \mathrm{~kg}$ ). The IV + IM group consisted of 3 males and 3 females (mean body weight, $9.7 \mathrm{~kg}$; range, 8.7 to $10.7 \mathrm{~kg}$ ).

Mean concentrations of cefazolin in interstitial fluid were measured for both groups (Figure 2; Table 1). Mean, minimum, and maximum concentrations of cefazolin obtained for the IV (Figure 3) and IV + IM (Figure 4) groups were plotted.

Comparing the mean cefazolin concentration in interstitial fluid between the IV and IV + IM groups revealed no significant difference at 1 hour (39.6 and $38.3 \mu \mathrm{g} / \mathrm{mL}$, respectively) and 1.5 hours ( 29.1 and $53.3 \mu \mathrm{g} / \mathrm{mL}$, respectively). However, the mean cefazolin concentration in interstitial fluid was significantly lower in the IV group, compared with the concentration in the IV + IM group, at $2(21.1$ and $46.4 \mu \mathrm{g} / \mathrm{mL}$, respectively; $P=0.001), 3(10.3$ and $31.7 \mu \mathrm{g} / \mathrm{mL}$, respectively; $P=0.002), 4(6.4$ and $19.1 \mu \mathrm{g} / \mathrm{mL}$, respectively; $P=0.042)$, and 5 (2.7 and 8.9 $\mu \mathrm{g} / \mathrm{mL}$, respectively; $P=0.003$ ) hours.

Comparing the mean values for pharmacokinetic parameters between the IV and IV + IM groups revealed a significant $(P=0.004)$ difference in $\operatorname{AUC}_{\mathrm{INF}}(74.99$ and $154.16 \mathrm{~h} \bullet \mu \mathrm{g} / \mathrm{mL}$, respectively; Table 2). In addition, the $\mathrm{AUC}_{\mathrm{INF}}$ was dose related. There was no significant difference between the IV and IV + IM groups for Cmax (37.3 and $51.5 \mu \mathrm{g} / \mathrm{mL}$, respectively), $\mathrm{t}_{1 / 2}$ (0.96 and 1.11 hours, respectively), and Tmax (1.28 and 1.65 hours, respectively). 


\section{Discussion}

On the basis of results of the present study, we accepted the hypothesis that doubling the dose of cefazolin (22 mg/kg, IV, and $22 \mathrm{mg} / \mathrm{kg}$, IM) adds 1 half-life to persistence of the drug. Although not significant, the half-life was approximately 15\% (approx. 10 minutes) longer for the IV + IM group, compared with the expected half-life if the IV dose had been doubled. There is a slightly longer drug exposure with every half-life. This slight increase in exposure time may be explained by a slower absorption rate when the drug is administered IM. After achieving equilibrium between the serum and interstitial fluid as a result of the IV injection of cefazolin, and given the constant elimination rate and low protein-binding capacity of the drug, the IM injection would increase the number of unbound molecules of cefazolin available for distribution for a longer period because of the higher total dose.

In the present study, we found that concentrations of cefazolin in interstitial fluid in all dogs were maintained above $4 \mu \mathrm{g} / \mathrm{mL}$ for 4 hours after a single injection of cefazolin $(22 \mathrm{mg} / \mathrm{kg}$, IV) and for 5 hours after injections of cefazolin (22 mg/kg, IV, and $22 \mathrm{mg} / \mathrm{k}$, IM; total dose, 44 $\mathrm{mg} / \mathrm{kg}$ ). This concentration should provide antimicrobial activity against the most common methicillin-susceptible commensal organisms on the skin of dogs (Staphylococcus pseudintermedius and Streptococcus spp) for clean surgical procedures. On the basis of these results, cefazolin (22 mg/kg, IV, and $22 \mathrm{mg} / \mathrm{kg}$, IM) administered 30 to 60 minutes before surgery for surgical procedures lasting $\leq 4$ hours would achieve and maintain the desired interstitial fluid concentrations. Cefazolin (22 mg/kg, IV) administered 30 to 60 minutes before surgery would maintain the interstitial fluid concentrations above the $\mathrm{MIC}_{90}$ for dogs undergoing short ( $\leq 3$ hours) surgical procedures. These recommendations were based on the lowest (minimum) cefazolin concentration, rather than on the mean concentration, to maintain targeted concentrations in all dogs in the present study to reduce the risk of developing an SSI. However further studies are needed to confirm clinical extrapolation of these data. In the event that surgical time exceeds the aforementioned durations, administration of another dose of cefazolin $(22 \mathrm{mg} / \mathrm{kg}, \mathrm{IV}$, at 4 hours after initial IV administration and $22 \mathrm{mg} / \mathrm{kg}$, IV, at 5 hours after the initial IV and IM administration of $44 \mathrm{mg} / \mathrm{kg}$ ) should maintain targeted concentrations in the interstitial fluid. 
Total drug exposure (AUCiNF) was approximately twice as high after $44 \mathrm{mg} / \mathrm{kg}$ (IV + IM group; $145.16 \mathrm{~h} \bullet \mu \mathrm{g} / \mathrm{mL}$ ), compared with the value after $22 \mathrm{mg} / \mathrm{kg}$ (IV group; $74.99 \mathrm{~h} \bullet \mu \mathrm{g} / \mathrm{mL}$ ), which suggested a dose-relation phenomenon. Interstitial fluid Cmax was less proportional (51.5 $\mu \mathrm{g} / \mathrm{mL}$ after $44 \mathrm{mg} / \mathrm{kg}$ and $37.3 \mu \mathrm{g} / \mathrm{kg}$ after $22 \mathrm{mg} / \mathrm{kg}$ ). The less-than-proportional Cmax most likely was attributable to a delay in Tmax caused by absorption of the IM portion of the dose. However because cephalosporins are concentration-dependent antimicrobials, the lower-thanproportional Cmax for the IV + IM group would not be detrimental and could be beneficial for decreasing concentration-dependent adverse effects, compared with results after IV administration of $44 \mathrm{mg} / \mathrm{kg}$.

Protein binding is a major factor for tissue distribution of a drug. ${ }^{21}$ To predict antimicrobial activity, it is important to know the concentration of the protein-unbound antimicrobial at the site of bacterial contamination (surgical site). Ultrafiltration provides a means for collecting protein-unbound cefazolin in the interstitial fluid by implantation of a semipermeable membrane in the tissue. Investigators of other studies ${ }^{25-27}$ have found that an ultrafiltration device is a reliable and convenient method for collecting interstitial fluid samples from tissues in dogs. This device has become the preferred method for collecting interstitial fluid, rather than collecting tissue biopsy specimens or using tissue cages, because of anatomic and physiologic relevance, lack of contamination from intracellular content, ease of insertion, collection of serial samples with the same device, and monitoring drug distribution in unrestrained animals. Furthermore, the ultrafiltration device provides a convenient method for continuous sample collection without residual wounds or lesions after removal of the ultrafiltration probes. ${ }^{21}$ To our knowledge, the study reported here was the first in which an ultrafiltration probe was used to determine the cefazolin concentration in interstitial fluid. By use of this device, we were able to detect a biologically accurate concentration of cefazolin in what we anticipate will be equivalent to the tissue biophase or surgical site, rather than in serum, which is a critical factor for determining the efficacy of agents used for prophylaxis against SSIs. ${ }^{30}$

Timing of antibiotic administration and redosing schedules are not always in accordance with institution guidelines. In 1 study, ${ }^{12}$ investigators found that $78 \%$ of dogs received the first 
antimicrobial dose before surgery; however, only $84 \%$ of those dogs received the dose within 60 minutes before the first incision. Twelve percent of dogs were initially treated during surgery (10 to 165 minutes after the first incision). ${ }^{12}$ If a guideline of repeated administration every 90 minutes after the first administration until closure of the surgical site were used, $51 \%$ of dogs received the required intraoperative administration, and 19\% of dogs that did not require intraoperative administration were treated. ${ }^{12}$ In a more recent study, ${ }^{23}$ investigators found a redosing incidence of $93.5 \%$, which they considered excellent; however, $28.4 \%$ of dogs received antimicrobials late, with the dose being administered more than 30 minutes late in $28 \%$ of those dogs. In the study reported here, administration of cefazolin (22 mg/kg, IV, and $22 \mathrm{mg} / \mathrm{kg}$, IM) before surgery results in antimicrobial concentrations that should be adequate against the most common skin contaminants for surgical procedures expected to last $\leq 4$ hours, and a redosing schedule would not be necessary.

The bacteria most commonly involved in SSIs in dogs and cats are commensal organisms on the skin (gram-positive cocci) and normal flora from the gastrointestinal and other tracts (predominantly gram-negative rods), depending on the surgical procedure. ${ }^{15,31}$ Historically, it has been recommended that time-dependent antimicrobials such as $\beta$-lactams be readministered during surgery every 2 half-lives to maintain therapeutic concentrations during surgery., $7,12,23$ Investigators of other studies have reported that the MIC 90 is 0.25 to $2 \mu \mathrm{g} / \mathrm{mL}$ for $S$ pseudintermedius, ${ }^{7,32,33} 4 \mu \mathrm{g} / \mathrm{mL}$ for Streptococcus spp, ${ }^{32,33}$ and $16 \mu \mathrm{g} / \mathrm{mL}$ for $E$ coli. ${ }^{7,24}$ A more recent study ${ }^{34}$ of $E$ coli revealed an MIC that inhibited $75 \%$ of isolates was $4 \mu \mathrm{g} / \mathrm{mL}$ and the $\mathrm{MIC}_{90}$ was $128 \mu \mathrm{g} / \mathrm{mL}$. It should be considered that although isolates were collected from 33 infection sites in that study, ${ }^{34}$ approximately $70 \%$ of the isolates were from the urinary tract, with the ear being a distant second (7.2\% of isolates), and no other body system providing more than $4 \%$ of isolates. These isolates may have been exposed to various courses of antimicrobials prior to isolation (i.e., recurrent urinary tract and otic infections) and may not be representative of bacteria that would typically be found in surgical patients.

The present study had some limitations. We were unable to determine pharmacokinetic parameters of cefazolin in serum because of presumed contamination of the percutaneous catheter with cefazolin during IV administration (data not included). Even if the drug residual in 
the catheter was $0.1 \%$, it would have biased the data substantially. Injection of the cefazolin and collection of blood samples were through the same catheter; therefore, the measured concentration of the drug in serum was not accurate, especially at early time points. Although we did not determine the pharmacokinetic parameters of cefazolin in serum, this information can be obtained from other studies..$^{2,7,22,30}$ Furthermore, the primary site of interest in the present study was interstitial fluid. The AUC for serum after administration of a dose of $40 \mathrm{mg} / \mathrm{kg}$ is 192.5 $\mathrm{h} \bullet \mu \mathrm{g} / \mathrm{mL}(11,548 \mu \mathrm{g} \bullet \mathrm{min} / \mathrm{mL})$, and $\mathrm{t}_{1 / 2}$ is 1.26 hours (75.8 minutes). ${ }^{22}$ The AUC for serum after administration of a dose of $20 \mathrm{mg} / \mathrm{kg}$ is $135.9 \mathrm{~h} \cdot \mu \mathrm{g} / \mathrm{mL}(8,158 \mu \mathrm{g} \bullet \mathrm{min} / \mathrm{mL})$, and $\mathrm{t}_{1 / 2}$ is 0.91 hours (5.08 minutes). ${ }^{7}$ Investigators of another study ${ }^{30}$ found the AUC for serum after administration of a dose of $20 \mathrm{mg} / \mathrm{kg}$ is $82.5 \mathrm{~h} \bullet \mu \mathrm{g} / \mathrm{mL}$, and $\mathrm{t}_{1 / 2}$ is 1.53 hours. In the present study, AUC for the interstitial fluid was $74.99 \mathrm{~h} \bullet \mu \mathrm{g} / \mathrm{mL}$ and $\mathrm{t}_{1 / 2}$ was 0.96 hours after IV administration of a dose of $22 \mathrm{mg} / \mathrm{kg}$ and AUC was $154.16 \mathrm{~h} \bullet \mu \mathrm{g} / \mathrm{mL}$ and t $1 / 2$ was 1.11 hours after administration of a dose of $44 \mathrm{mg} / \mathrm{kg}$ (22 mg/kg, IV, and $22 \mathrm{mg} / \mathrm{kg}$, IM). These results indicated that exposure to cefazolin after administration was extremely similar in the interstitial fluid and serum, which would indicate good penetration of the antimicrobial into a surgical site.

Purpose-bred research Beagles that were considered healthy were used in the present study. This may not have been representative of the general population because there are patient variations associated with breed and size that may alter pharmacokinetics of cefazolin. Patients with underlying conditions or metabolic diseases that may increase glomerular filtration rate may also have increased clearance of cefazolin. ${ }^{35}$

Dogs in the present study were not anesthetized and not subjected to surgical conditions. Some operative factors, including prolonged anesthesia time, surgical procedures requiring $>90$ minutes for completion, use of certain anesthetic drugs, and hypothermia, can result in a greater risk of SSI, possibly because of increased bacterial contamination, excessive tissue manipulation, and dehydration. ${ }^{1,15,23,26}$ It has been suggested ${ }^{35}$ that substantial hemorrhage necessitating volume expansion, blood transfusion, and vasopressor or inotropic administration may dilute or increase the clearance of hydrophilic compounds (including cephalosporins), which thereby decreases concentration of the drug. ${ }^{35}$ 
Data for the present study supported clinical use such that a regimen of a total dose of 44 $\mathrm{mg}$ of cefazolin/ $\mathrm{kg}(22 \mathrm{mg} / \mathrm{kg}, \mathrm{IV}$, and $22 \mathrm{mg} / \mathrm{kg}$, IM) administered 30 to 60 minutes before surgical procedures expected to last $\leq 4$ hours and a single injection of cefazolin $(22 \mathrm{mg} / \mathrm{kg}, \mathrm{IV})$ administered 30 to 60 before surgical procedures expected to last $\leq 3$ hours should provide protection against the most common contaminants on the skin of dogs and cats $(S$ pseudintermedius and Streptococcus spp). However, if E coli or other gram-negative bacteria are suspected, another antimicrobial and dosing regimen should be considered. Further studies are needed to validate these results in clinical settings and to assess interstitial fluid pharmacokinetics of cefazolin in anesthetized patients undergoing surgery. 


\section{Figures}

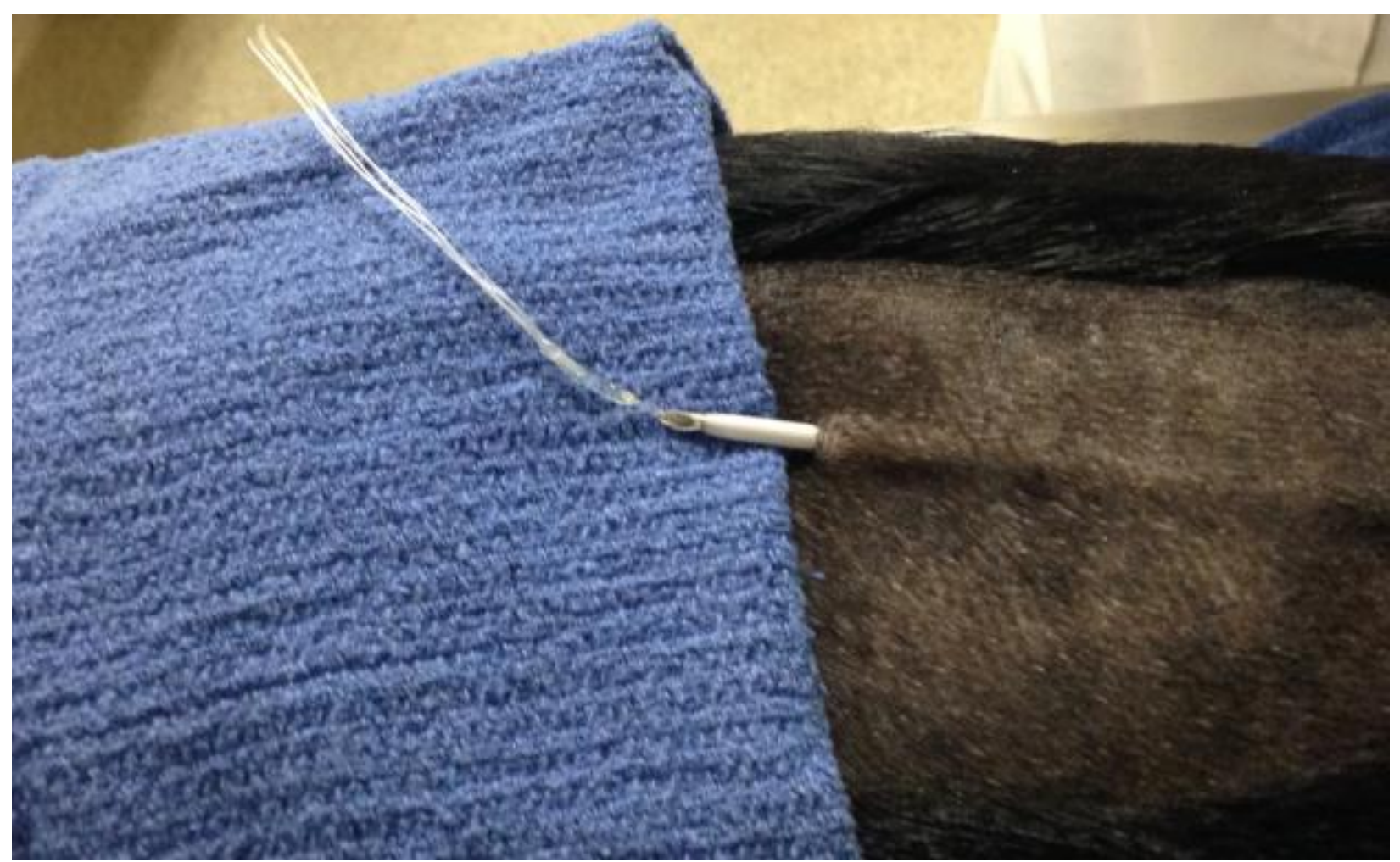

Figure 1 - Semipermeable ultrafiltration probe threaded from cranial to caudal into the introducer needle to be placed subcutaneously. 


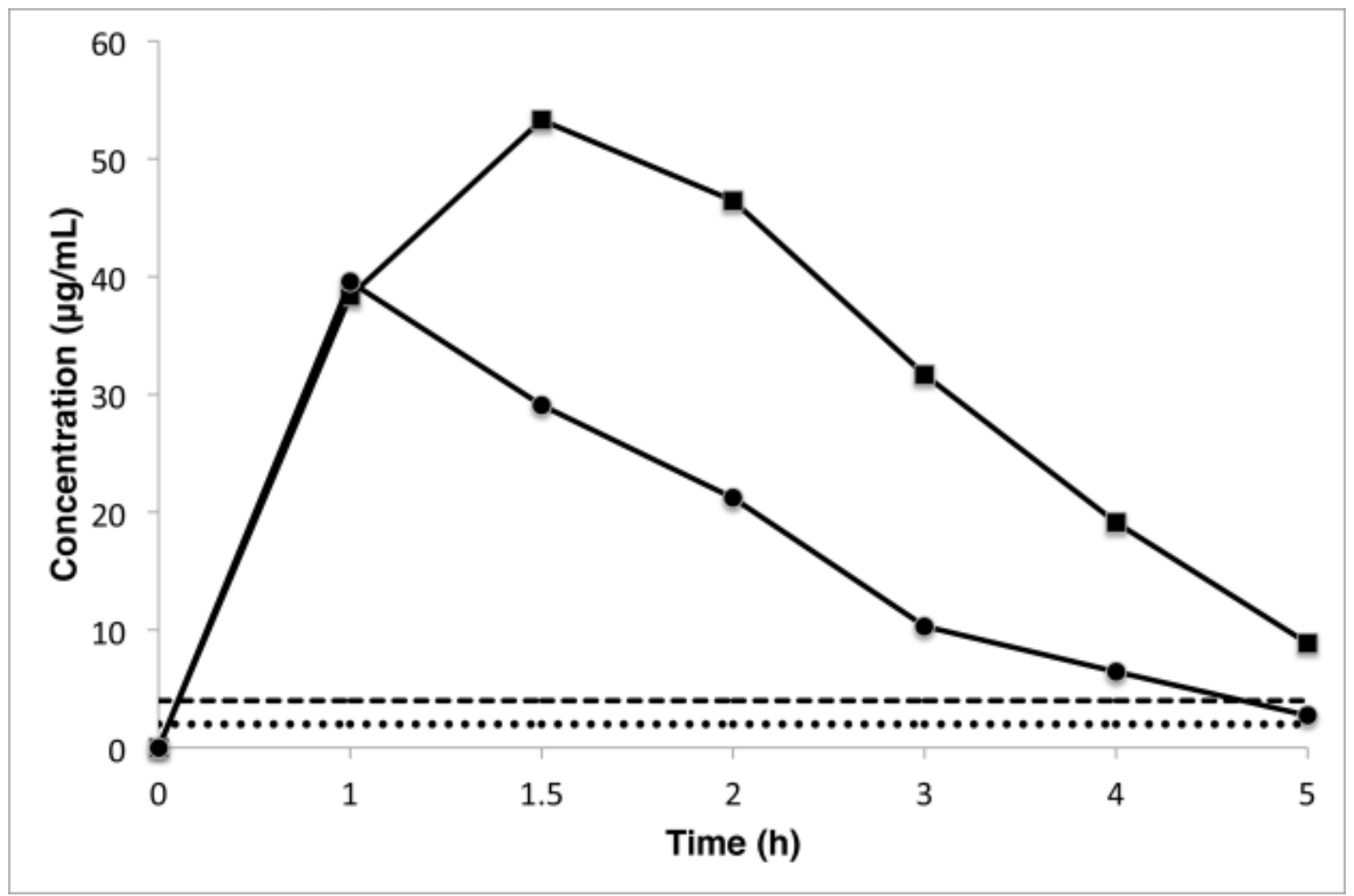

Figure 2 - Mean cefazolin concentration-time curve for concentrations in interstitial fluid after administration of a single dose (22 $\mathrm{mg} / \mathrm{kg}$, IV) to $5 \mathrm{dogs}$ (IV group [circles]) and simultaneous IV and IM administration ( $22 \mathrm{mg} / \mathrm{kg}$, IV, and $22 \mathrm{mg} / \mathrm{kg}$, IM) to $6 \mathrm{dogs}$ (IV + IM group [squares]). Notice the $\mathrm{MIC}_{90}$ for Streptococcus $\operatorname{spp}(4 \mu \mathrm{g} / \mathrm{mL}$ [dashed line]) and the MIC 90 for Staphylococcus pseudintermedius $(2 \mu \mathrm{g} / \mathrm{mL}$ [dotted line]). 


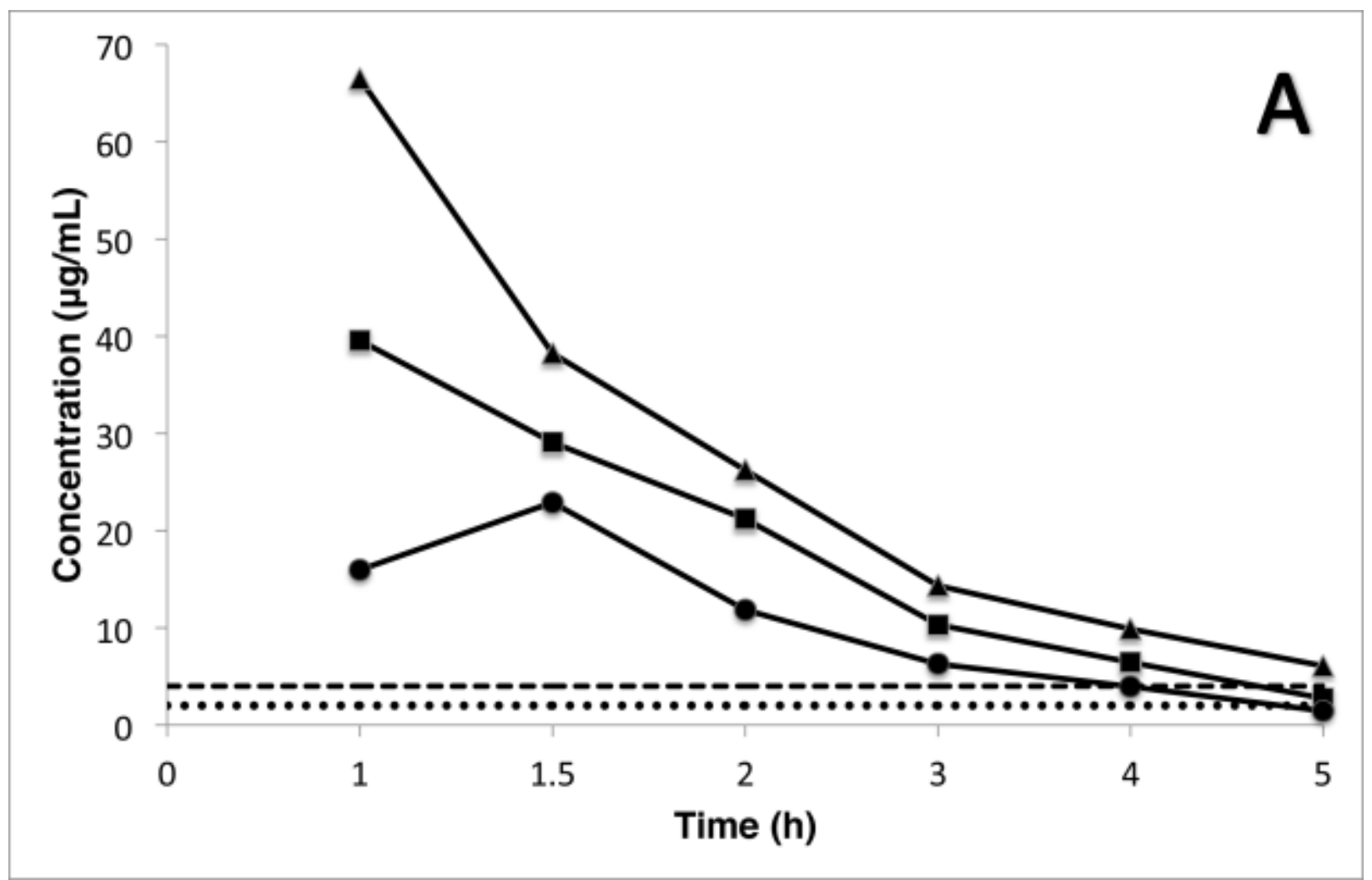

Figure 3 - Cefazolin concentration-time curves of the mean (squares), minimum (circles), and maximum (triangles) concentrations in interstitial fluid after administration of a single dose (22 $\mathrm{mg} / \mathrm{kg}$, IV) to 5 dogs (IV group [A]). Notice the MIC 90 for Streptococcus spp (4 $\mu \mathrm{g} / \mathrm{mL}$ [dashed line]) and the MIC 90 for Staphylococcus pseudintermedius $(2 \mu \mathrm{g} / \mathrm{mL}$ [dotted line]). 


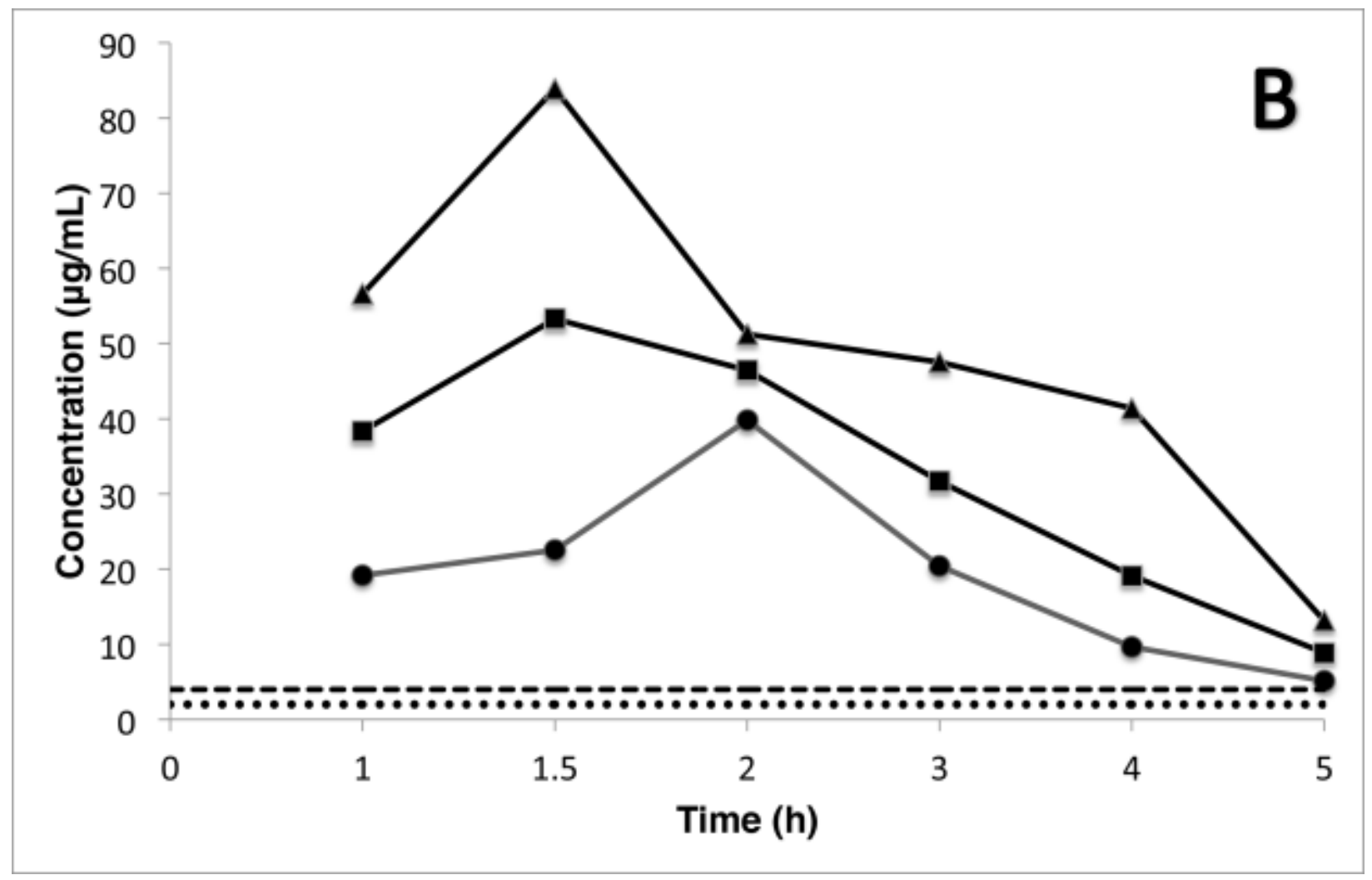

Figure 4 - Cefazolin concentration-time curves of the mean (squares), minimum (circles), and maximum (triangles) concentrations in interstitial fluid after administration of a simultaneous IV and IM administration (22 mg/kg, IV, and $22 \mathrm{mg} / \mathrm{kg}$, IM) to $6 \mathrm{dogs}$ (IV + IM group [B]). Notice the MIC 90 for Streptococcus spp ( $4 \mu \mathrm{g} / \mathrm{mL}$ [dashed line]) and the MIC 90 for Staphylococcus pseudintermedius $(2 \mu \mathrm{g} / \mathrm{mL}$ [dotted line]). 


\section{Tables}

Table 1 - Mean, minimum, and maximum concentrations of cefazolin $(\mu \mathrm{g} / \mathrm{kg})$ in interstitial fluid after administration of a single dose (22 mg/kg, IV) to $5 \mathrm{dogs}$ (IV group) and simultaneous IV and IM administration (22 mg/kg, IV, and $22 \mathrm{mg} / \mathrm{kg}$, IM) to $6 \mathrm{dogs}$ (IV + IM group).

\begin{tabular}{|c|c|c|c|c|c|c|c|}
\hline \multicolumn{4}{|c|}{ IV group } & \multicolumn{3}{|c|}{ IV + IM group } & \multirow[b]{2}{*}{$P$ value* } \\
\hline Time (h & Mean & Minimum & Maximum & Mean & Minimum & Maximum & \\
\hline 1 & 39.6 & 16.0 & 66.5 & 38.3 & 19.2 & 56.6 & 0.924 \\
\hline 1.5 & 29.1 & 22.9 & 38.2 & 53.3 & 22.5 & 83.9 & 0.054 \\
\hline 2 & 21.2 & 11.8 & 26.2 & 46.4 & 39.8 & 51.2 & 0.001 \\
\hline 3 & 10.3 & 6.3 & 14.3 & 31.7 & 20.4 & 47.5 & 0.002 \\
\hline 4 & 6.4 & 4.0 & 9.9 & 19.1 & 9.7 & 41.4 & 0.042 \\
\hline 5 & 2.7 & 1.4 & 6.1 & 8.9 & 5.1 & 13.2 & 0.003 \\
\hline
\end{tabular}

*Comparison of mean values between groups; results were significant at $P<0.05$.

Table 2 - Pharmacokinetics of cefazolin after administration of a single dose ( $22 \mathrm{mg} / \mathrm{kg}$, IV) to 5 dogs (IV group) and simultaneous IV and IM administration (22 mg/kg, IV, and $22 \mathrm{mg} / \mathrm{kg}, \mathrm{IM})$ to 6 dogs (IV + IM group).

\begin{tabular}{|c|c|c|c|c|c|c|c|}
\hline \multirow[b]{2}{*}{ Parameter } & \multicolumn{3}{|c|}{ IV group } & \multicolumn{3}{|c|}{ IV + IM group } & \multirow[b]{2}{*}{$P$ value* } \\
\hline & Mean & Minimum & Maximum & Mean & Minimum & Maximum & \\
\hline $\operatorname{AUC}_{\text {INF }}(h \bullet \mu \mathrm{g} / \mathrm{mL})$ & 74.99 & 49.60 & 97.01 & 154.16 & 115.14 & 223.24 & 0.004 \\
\hline $\mathrm{Cmax}(\mu \mathrm{g} / \mathrm{mL})$ & 37.3 & 22.9 & 66.5 & 51.5 & 26.4 & 83.9 & 0.177 \\
\hline $\mathrm{t}_{1 / 2}(\mathrm{~h})$ & 0.96 & 0.63 & 1.28 & 1.11 & 0.84 & 1.52 & 0.429 \\
\hline $\operatorname{Tmax}(\mathrm{h})$ & 1.28 & 1.00 & 1.50 & 1.65 & 1.00 & 3.00 & 0.247 \\
\hline
\end{tabular}

*Comparison of mean values between groups; results were significant at $P<0.05$. 


\section{Footnotes}

a. Dexdomitor, Zoetis, Florham Park, NJ.

b. Model MF-7023, BASi, West Lafayette, Ind.

c. $\quad 2 \%$ lidocaine hydrochloride, Hospira Inc, Lake Forest, Ill.

d. Ethilon 3-0, Ethicon, Somerville, NJ

e. Model MD-1320, BASi, West Lafayette, Ind.

f. Antisedan, Zoetis, Florham Park, NJ.

g. Microsoft Office Excel 2011, Microsoft Corp, Redmond, Wash.

h. Cefazolin, Westward Pharmaceutical, Eatontown, NJ.

i. $\quad$ Fisher Scientific, Pittsburgh, Pa.

j. $\quad$ BD, Franklin Lakes, NJ.

k. Acquity UPLC, Waters Corp, Milford, Mass.

1. 50 X $2.1 \mathrm{~mm}, 2.7 \mu \mathrm{m}$ pore size, Cortecs, Waters Corp, Milford Mass.

m. WINKS SDA 6, version 6.0.93, Texasoft Inc, Cedar Hill, Tex.

n. Phoenix 64, Certara, Princeton, NJ.

o. Sigma Plot 12.5, Systat Software, Chicago, Ill. 


\section{REFERENCES}

1. Brown DC, Conzemius MG, Shofer S, et al. Epidemiologic evaluation of postoperative wound infections in dogs and cats. J Am Vet Med Assoc 1997;210:1302-1306.

2. Kenneth SS, Wroczynski F, Jones CW. Duration of antibiotic prophylaxis. Am J Surg 1986;151:209-212.1

3. Whittem TL, Johnson AL, Smith CW, et al. Effect of perioperative prophylactic antimicrobial treatment in dogs undergoing elective orthopedic surger. J Am Vet Med Assoc 1999;215:212-216.

4. Prospero E, Barbadoro P, Marigliano A, et al. Perioperative antibiotic prophylaxis: improved compliance and impact on infection rates. Epidemiol Infect 2011;139:13261331.

5. Xu SG, Mao ZG, Liu BS, et al. Evaluating the use of antibiotic prophylaxis during open reduction and internal fixation surgery in patients at low risk of surgical site infection. Injury 2015;46:184-188.

6. Kaiser AB. Antimicrobial prophylaxis in surgery. N Engl J Med 1986;315:1129-1138.

7. Rosin E, Uphoff TS, Schultz-Darken NJ, et al. Cefazolin antibacterial activity and concentrations in serum and the surgical wound in dogs. Am J Vet Res 1993;54:13171321.

8. Marcellin-Little DJ, Papich MG, Richardson DC, et al. Pharmacokinetic model for cefazolin distribution during total hip arthroplasty in dogs. Am J Vet Res 1996;57:720 723.

9. Wilkens B, Sullivan P, McDonald TP, et al. Effects of cephalothin, cefazolin, and cefmetazole on the hemostatic mechanism in normal dogs: implications for the surgical patient. Vet Surg 1995;24:25-31.

10. Hauser CJ, Adams CA Jr, Eachempati SR. Surgical Infection Society guideline:

prophylactic antibiotic use in open fractures: an evidence-based guideline. Surg Infect (Larchmt) 2006;7:379-405.

11. Mangram AJ, Horan TC, Pearson ML, et al. Guideline for prevention of surgical site infection. Am J Infect Control 1999;27:97-132.

12. Weese JS, Halling KB. Perioperative administration of antimicrobials associated with elective surgery for cranial cruciate ligament rupture in dogs: 83 cases (2003-2005). $J$ Am Vet Med Assoc 2006;229:92-95. 
13. Casale SA, McCarthy RJ. Complications associated with lateral fabellotibial suture surgery for cranial cruciate ligament injury in dogs: 363 cases (1997-2005). J Am Vet Med Assoc 2009;234:229-235.

14. Nicholson M, Beal M, Shofer F, et al. Epidemiologic evaluation of postoperative wound infection in clean-contaminated wounds: a retrospective study of 239 dogs and cats. Vet Surg 2002;31:577-581.

15. Knights CB, Mateus A, Baines SJ. Current British veterinary attitudes to the use of perioperative antimicrobials in small animal surgery. Vet Rec 2012;170:646-652.

16. Daude-Lagrave A, Carozzo C, Fayolle P, et al. Infection rates in surgical procedures: a comparison of cefalexin vs a placebo. Vet Comp Orthop Traumatol 2001;14:146-150.

17. Martin C, Pourriat JL. Quality of postoperative antibiotic administration by French anaesthetists. J Hosp Infect 1998;40:47-53.

18. Song F, Glenny AM. Antimicrobial prophylaxis in colorectal surgery: a systematic review of randomized controlled trials. Br J Surg 1998;85:1232-1241.

19. Heineck I, Ferreira MB, Schenkel EP. Prescribing practice for antibiotic prophylaxis for 3 commonly performed surgeries in a teaching hospital in Brazil. Am J Infect Control 1999;27:296-300.

20. Zanetti G, Flanagan HL, Cohn LH, et al. Improvement of intraoperative antibiotic prophylaxis in prolonged cardiac surgery by automated alerts in the operating room. Infect Control Hosp Epidemiol 2003;24:13-16.

21. Papich MG, Davis JL, Floerchinger AM. Pharmacokinetics, protein binding, and tissue distribution of orally administered cefpodoxime proxetil and cephalexin in dogs. Am J Vet Res 2010;71:1484-1491.

22. Rosin E, Ebert S, Uphoff TS, et al. Penetration of antibiotics into the surgical wound in a canine model. Antimicrob Agents Chemother 1989;33:700-704.

23. Nazarali A, Singh A, Weese JS. Perioperative administration of antimicrobials during tibial plateau leveling osteotomy. Vet Surg 2014;43:966-971.

24. Petersen SW, Rosin E. Cephalothin and cefazolin in vitro antibacterial activity and pharmacokinetics in dogs. Vet Surg 1995;24:347-351.

25. Bidgood TL, Papich MG. Comparison of plasma and interstitial fluid concentrations of doxycycline and meropenem following constant rate intravenous infusion in dogs. Am $J$ Vet Res 2003;64:1040-1046. 
26. Bidgood TL, Papich MG. Plasma and interstitial fluid pharmacokinetics of enrofloxacin, its metabolite ciprofloxacin, and marbofloxacin after oral administration and a constant rate intravenous infusion in dogs. $J$ Vet Pharmacol Ther 2005;28:329-341.

27. Bidgood TL, Papich MG. Plasma pharmacokinetics and tissue fluid concentrations of meropenem after intravenous and subcutaneous administration in dogs. Am J Vet Res 2002;63:1622-1628.

28. Julious SA, Debarnot CA. Geometric means justification for PK data. J Biopharm Stat 2000;10:55-71.

29. Powers J. Statistical analysis of PK data. J Vet Pharmacol Ther 1990;13:115-120.

30. Matushek KJ, Rosin E. Pharmacokinetics of cefazolin applied topically to the surgical wound. Arch Surg 1991;126:890-893.

31. Owen LJ, Gines JA, Knowles TJ, et al. Efficacy of adhesive incise drapes in preventing bacterial contamination of clean canine surgical wounds. Vet Surg 2009;38:732-737.

32. Stegemann MR, Passmore CA, Sherington J, et al. Antimicrobial activity and spectrum of cefovecin, a new extended-spectrum cephalosporin, against pathogens collected from dogs and cats in Europe and North America. Antimicrob Agents Chemother 2006;50:2286-2292.

33. Westermeyer RR, Roy AF, Mitchell MS, et al. In vitro comparison of staphylococcus pseudintermedius susceptibility to common cephalosporins used in dogs. Vet Ther 2010;11:E1-E9.

34. Thungrat K, Price SB, Carpenter M, et al. Antimicrobial susceptibility patterns of clinical Escherichia coli isolates from dogs and cats in the United States: January 2008 through January 2013. Vet Microbiol 2015;179:287-295.

35. Douglas A, Udy AA, Wallis SC, et al. Plasma and tissue pharmacokinetics of cefazolin in patients undergoing elective and semielective abdominal aortic aneurysm open repair surgery. Antimicrob Agents Chemother 2011;55:5238-5242. 


\section{Appendix A - BASi ${ }^{\circledR}$ Ultrafiltration Probe Image}

\section{UF - 3-12 Ultrafiltration Probe}

3 loops of membrane

each has $2 \mathrm{~cm}$ of membrane

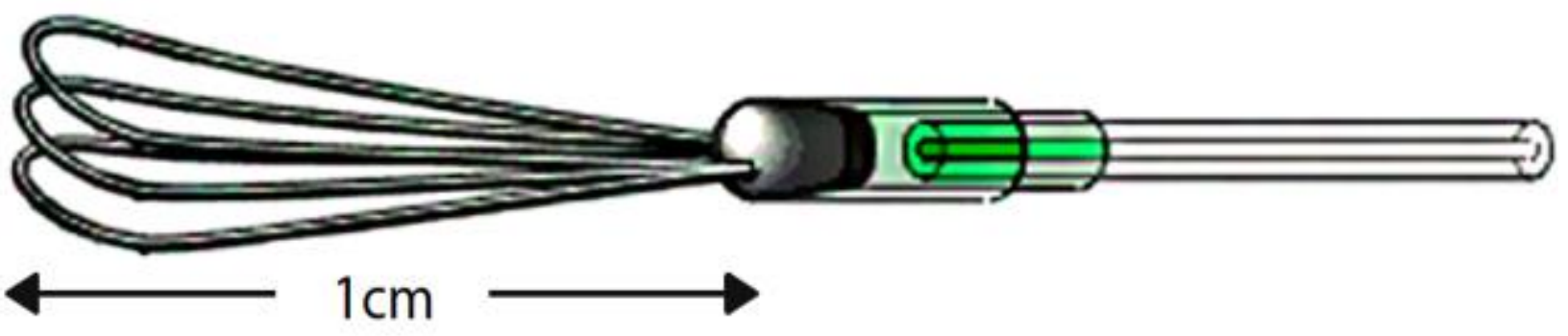

The $2 \mathrm{~cm}$ membrane in each loop is folded in half, so that the length of the membrane loop is half the length of the membrane, or $1 \mathrm{~cm}$ in this example

Figure A.1 UF-3-12 ultrafiltration sampling probe used in this study, with $29-\mu \mathrm{L}$ volume capacity. 